\title{
TENDÊNCIAS E USO DE REPOSITÓRIOS DE ACESSO ABERTO
}

Resumo: Estudo descritivo com o emprego do levantamento bibliográfico para a contextualização do tema no período de 2006 a 2018. A coleta e análise de dados foram obtidos na BDTD e SciELO, com enfoque nas publicações em que os repositórios de acesso aberto eram objetos de estudo. Teve como objetivo verificar nas pesquisas de teses, dissertações e artigos quais foram as aplicações dos estudos sobre repositórios. E refletir sob a aplicação dos repositórios sob a ótica do movimento do acesso aberto. Os resultados demonstraram que os estudos seguem três vieses específicos: a) estudos de repositório em âmbito internacional e nacional: América Latina, Caribe, Argentina, Cuba, Brasil; b) estudos de casos em repositórios de universidades e instituição de pesquisa; c) estudos com análise administrativa e técnica (indexação, recuperação e representação informacional, entre outros). Conclui-se, com base nos dados obtidos que os repositórios de acesso aberto são recursos estruturados benéficos para organização, gestão e preservação da informação em diversos suportes informacionais. O estudo mostrou que o Brasil tem desenvolvido pesquisas, ainda que tímidas, com foco na aplicação de repositórios internacionais, nacionais ou institucionais.

Palavras-chave: Repositórios internacionais. Repositórios nacionais. Repositórios institucionais. Acesso aberto.
Juliana Fachin

Doutoranda do programa de pós-graduação em Ciência da Informação da Universidade Federal de Santa Catarina -UFSC. Bolsista Capes.julianafachin@gmail.com

Ursula Blattmann

Prof. Dra. na Universidade Federal de Santa Catarina, Florianópolis Brasil ublattmann@gmail.com

Clarice Fortkamp Caldin

Prof. Dra. na Universidade Federal de Santa Catarina, Florianópolis Brasil claricefcaldin@hotmail.com

\section{TRENDS AND USE OF OPEN ACCESS REPOSITORIES}

\begin{abstract}
Descriptive study with the use of bibliographic survey to contextualize the theme from 2006 to 2018. Data collection and analysis were obtained from BDTD and SciELO, focusing on publications in which open access repositories were objects of study. It aimed to verify in the research of theses, dissertations and articles which were the applications of studies on repositories. And reflect on the application of repositories from the perspective of the movement of open access. The results showed that the studies follow three specific biases: a) international and national repository studies: Latin America, Caribbean, Argentina, Cuba, Brazil; b) case studies in university repositories and research institutions; c) studies with administrative and technical analysis (indexing, retrieval and informational representation, among others). It is concluded, based on the data obtained that open access repositories are beneficial structured resources for the organization, management and preservation of information in various informational supports. The study showed that Brazil has been developing research, albeit timid, focusing on the application of international, national or institutional repositories.
\end{abstract}

Keywords: International repositories. National repositories. Institutional repositories. Open access. 


\section{TENDENCIAS Y USO DE REPOSITORIOS DE ACCESO ABIERTO}

Resumen: Estudio descriptivo utilizando la encuesta bibliográfica para contextualizar el tema de 2006 a 2018. La recopilación y el análisis de datos se obtuvieron de BDTD y SciELO, centrándose en publicaciones en las que los repositorios de acceso abierto eran objetos de estudio. Su objetivo era verificar en la investigación de tesis, disertaciones y artículos las aplicaciones de los estudios sobre repositorios. Y reflexionar sobre la aplicación de repositorios desde la perspectiva del movimiento de acceso abierto. Los resultados mostraron que los estudios siguen tres sesgos específicos: a) estudios de repositorios internacionales y nacionales: América Latina, el Caribe, Argentina, Cuba, Brasil; b) estudios de caso en repositorios universitarios e instituciones de investigación; c) estudios con análisis administrativo y técnico (indexación, recuperación y representación informativa, entre otros). Se concluye, en base a los datos obtenidos que los repositorios de acceso abierto son recursos estructurados beneficiosos para la organización, gestión y preservación de la información en diversos soportes informativos. El estudio demostró que Brasil ha estado desarrollando investigaciones, aunque tímidas, centrándose en la aplicación de repositorios internacionales, nacionales o institucionales.

Palabras clave: Repositorios internacionales. Repositorios nacionales. Repositorios institucionales. Acceso abierto.

\section{INTRODUÇÃO}

A informação é valiosa para a humanidade e se não for devidamente organizada muitas coisas podem se perder no emaranhado de páginas e sistemas de armazenamento. Castells (2015) advoga que a informação e a comunicação constituem a base do desenvolvimento científico e social do ser humano. Sendo a informação de suma importância para a humanidade, a organização para sua recuperação e acesso são temas pertinentes a serem discutidos.

Lembra-se que Paul Otlet, em seu tempo, buscou difundir a visão da organização e representação do conhecimento voltado para o acesso do acervo universal disponível para todos. Em 1895 Otlet desenvolveu o Répertoire Bibliographique Universel (RBU), no sentido de compilar manualmente uma bibliografia planetária e prover a organização e recuperação do conhecimento mundial. Registou em 1939 mais de 12 milhões de entradas para os registros do acervo em fichas catalográficas e em registros tombados (UNION OF INTERNATIONAL ASSOCIATIONS, 2018).

De fato, é na interseção entre a teoria e a prática que se pauta o processo de organização da informação, entendido como uma série de ações sistemáticas dinâmicas que acolhe e divulga medidas apropriadas para gerir de forma eficiente, racional e funcional os objetos informacionais em sistemas estruturados. Gleick (2013) apresenta os grandes projetos 
de tratamento e organização da informação, como o caso de Claude Shannon, quando relacionou o maior repositório de informações da época com a Biblioteca do Congresso Norte-americano.

Assim, a necessidade de organizar a massa informacional fez com que a comunidade científica se mobilizasse e criasse vários mecanismos de representação e organização de acervos, como é o caso do controle bibliográfico, catalogação, classificação, sistema de concessão de direitos autorais, ontologias e semânticas para bases e bancos de dados, ordenação de acervos físicos e eletrônicos em sistemas estruturados. Conforme Atkins (2009, p.33, tradução nossa) "Os conjuntos de dados estão se tornando os novos instrumentos da ciência", ou seja, existe a preocupação de que a humanidade possa ter acesso ao conhecimento que foi e está sendo criado.

O uso de repositórios, ambientes constituídos de acervos digitais de diferentes tipos documentais, temas e até mesmo de dados, tendem a facilitar a organização e representação da informação, assim como possibilita o acesso aberto à massa informacional de uma instituição em um único sistema/local, principalmente com o emprego de software livre (IBICT, 2018).

Dentro deste pressuposto, justifica-se o foco deste estudo na necessidade de explorar campos organizacionais existentes, a fim de atender demandas informacionais latentes da sociedade. Alvarenga (2013) indica que os profissionais da ciência da informação devem desempenhar a função de investigadores e desenvolver, além das práticas e técnicas, serviços com conexão entre os usuários e os sistemas de representação e recuperação da informação. A Ciência da Informação (CI) se preocupa com a informação em seus diferentes suportes. Podese mesmo dizer que o objeto de estudo da CI se pauta na necessidade informacional social, a qual enreda o acesso aberto ao conteúdo científico, administrativo e técnico. Mas é de fundamental importância saber como organizar o conhecimento de forma a disseminá-lo amplamente, como visa o acesso aberto.

Neste sentido, almejou verificar nas pesquisas de teses, dissertações e artigos quais foram as aplicações dos estudos sobre repositórios. E, intenta-se fomentar reflexões quanto a aplicação dos repositórios sob a ótica do movimento do acesso aberto. Vislumbrando a ferramenta como objeto para a organização e acesso à massa informacional de diferentes formatos e suportes, agrupados em um único local as informações de interesse para a sociedade. 


\section{CENÁRIO DO MOVIMENTO DO ACESSO ABERTO}

Entende-se que o acesso aberto é um meio de disseminação do conhecimento sem restrições de fronteiras, taxas, com o consentimento do autor na disponibilização do conteúdo, de forma a socializar rapidamente as pesquisas e os pesquisadores.

Partindo deste princípio, a tendência dos movimentos Open tem crescido e tomado vários formatos, como o caso do: Open Science (Ciência Aberta), Open Books (Livro Aberto), Open Data (Dados Abertos); exige-se qualidade ao se publicar no acesso aberto, como ao citar dados abertos, quanto ao uso das identidades de autor como ORCID ${ }^{1}$ e DOI $^{2}$ para as publicações nas políticas informacionais de acesso, por exemplo. Pode-se mesmo afirmar que vários movimentos de apoio ao acesso aberto têm sido bastante representativos na atual sociedade, principalmente para fazer pressão da gestão pública em adotar modelos igualitários de acesso ao conhecimento.

As declarações de apoio ao acesso aberto permeiam um longo percurso, o qual pode ser observado no histórico do Open Access Directory - Diretório de acesso aberto, criado em 2008 pela Escola de Biblioteconomia e Ciência da Informação do Simmons College - Boston, EUA, ao acompanhar e organizar informações sobre o movimento do acesso aberto desde os primeiros manifestos (SIMMONS, 2018).

Entre as declarações mais recentes de apoio ao movimento de acesso aberto destacase:

a) $\quad 12$ de junho de 2012 - Recursos Abertos Educacionais de Paris, conhecido como o The Paris OER (Open Educational Resources), Declaração oriunda do Congresso Global da UNESCO com intuito de disponibilizar material educacional pelos governos;

b) 22 de outubro de 2013 - a Declaração de Dados Abertos (Open Data) vinda da Iniciativa de Dados Abertos Globais (Global Open Data Initiative), no sentido de que os governos disponibilizem os seus dados de forma aberta a todos;

c) 23 de maio de 2014 - a Declaração de acesso aberto da área de Biblioteconomia e Ciência da Informação (LIS Open Access Declaration), com a intenção de possibilitar o acesso aberto aos trabalhos, conforme os princípios da Iniciativa de Budapeste

\footnotetext{
${ }^{1}$ ORCID - ID Aberto de Pesquisador e Contribuidor. Visa identifica internacionalmente a produção científica de um autor, segue o formato de um currículo. Veja sobre o assunto em: https://orcid.org/.

2 O DOI - Identificador de objeto digital, é um projeto desenvolvido para o registro de publicações científicas, expandido para outros materiais, suportes e formatos, porém, esse serviço contém custos. Veja sobre o assunto em: https://www.doi.org/.
} 
de acesso aberto (Budapest Open Access Initiative), e da IFLA sobre o acesso aberto para a Literatura Acadêmica e de Documentos de Pesquisa (Statementon Open Access to Scholarly Literatureand Research Documentation);

d) 09 de outubro de 2014 - A Declaração de Haia sobre a Descoberta de Conhecimento na Era Digital, a qual visa que todos os dados de pesquisa fiquem abertos e acessíveis;

e) $\quad$ 09-10 de novembro de 2015 - Declaração do Conselho Latino-Americano de Ciências Sociais (CLACSO) sobre o acesso aberto ao conhecimento como um bem comum da comunidade acadêmica;

f) 27 de maio de 2016 - Declaração da União Europeia, a qual estipula até 2020 para que toda a produção de pesquisa científica, financiada com verba pública esteja disponível em acesso aberto;

g) 05 de setembro de 2016 - Declaração Conjunta da Confederation of Open Access Repositories - COAR - UNESCO sobre o acesso aberto. Reafirma o compromisso de avançar a agenda no contexto amplo do desenvolvimento sustentável e busca meios de reduzir custos, fortalecer o apoio a instituições com menores orçamentos e em países em desenvolvimento no sentido de compartilhar recursos informacionais.

Para discutir as práticas, conduta ética, tendências e modelos do movimento open, são realizados eventos específicos sobre o tema; OASP (2018) indica como relevante os:

a) COASP - Conferenceon Open Access Scholarly Publishing ${ }^{3}$. É um evento itinerante que visa discutir a Publicação Científica de Acesso Aberto;

b) CONFOA - Conferência Luso-Brasileira sobre acesso aberto ${ }^{4}$. Em 2009 Portugal e Brasil fizeram um acordo de agenciar ações e eventos para promover o acesso aberto nos países. Desde então, cada edição do evento acontece em um dos dois países.

c) CLACSO's Open Access Indicators and Scholarly Communications in LatinAmerica 2014, considerado uma marca de estratégia da UNESCO para o acesso aberto, em que 196 países endossaram um documento ${ }^{5}$ com orientações sobre o acesso em instituições de pesquisa;

d) COUNCIL OF THE EUROPEAN UNION - Política da Comunidade Comum Europeia 2016, em que foi aprovado o planejamento "HORIZON 2020" possibilitando o

\footnotetext{
${ }^{3}$ Anais do COASP: https://oaspa.org/conference/.

${ }^{4}$ Anais do CONFOA: http://confoa.rcaap.pt/2019/apresentacao/eventos-anteriores/.

${ }^{5}$ Documanro da LACSO's 2014: http://biblioteca.clacso.edu.ar/clacso/se/20140917054406/OpenAccess.pdf.
} 
acesso aberto para todas as publicações científicas e aos dados de pesquisa que obtiverem financiamento da Comunidade Europeia ${ }^{6}$;

e) Open Access Week - Semana Internacional do acesso aberto ${ }^{7}$. Evento global que discute sobre o acesso aberto, promove cursos, palestras, oficinas e seminários. As primeiras atividades do evento datam de 2010 e continuam até os dias atuais;

f) Conferência 20 do $\mathrm{SciELO}^{8}$ quem ocorreu em 2018. Neste evento foram discutidas as tendências de publicação científica de acesso aberto na América Latina;

g) ALPSP - Conference is for everyone in the scholarly publishing 9 . Acontece todo ano desde a primeira edição em 2016; o evento visa promover o debate em torno das tendências da publicação científica e do acesso a esse conteúdo;

h) USETDA ${ }^{10}$. Iniciou em 2011 e segue até os dias atuais; o evento discute sobre a comunicações acadêmicas na educação de pós-graduação;

i) Making Science FAIR: Beilstein Open Science Symposium ${ }^{11}$. Desde 2017 o Simpósio de Ciência Aberta da Alemanha discute as tendências desse movimento.

Destaca-se a obra da European University Association: EUA's open accesschecklist for universities: a practicalguideonimplementation de 2015 (EUA'S, 2015), na qual observase a importância de se desenvolver políticas institucionais e públicas de acesso aberto para as publicações de pesquisa, principalmente as científicas.

Destaca-se também, o projeto FOSTER - Promoção da implementação prática do Open Science no Horizonte 2020, que intenta desenvolver políticas para promoção do desenvolvimento e publicação de pesquisa orientada para o acesso aberto em toda União Europeia, cujo "objetivo é contribuir para uma mudança real e duradoura no comportamento dos pesquisadores europeus para garantir que a Open Science (OS) se torne a norma" (FOSTER, 2018, tradução nossa).

Estudos do Banco Mundial (2018) destacam o valor intrínseco desse tipo de ação (disponibilizar dados de pesquisa em open access), porém recomendam que esses dados sejam refinados ou transformados para revelar o seu potencial. Os benefícios incluem a transparência, melhoria no serviço público, inovação e valores econômicos e eficiência.

\footnotetext{
${ }^{6}$ Política de acesso à publicação científica da União Européia: https://ec.europa.eu/programmes/horizon2020/.

${ }^{7}$ Eventos da Semana do Acesso Aberto: http://www.openaccessweek.org/events.

${ }^{8}$ Evento SciELO 20 anos: https://www.scielo20.org/.

${ }^{9}$ Anais das Conferências da ALPSP: https://www.alpsp.org/Conference.

${ }^{10}$ Conferências da USETDA : https://www.usetda.org/usetda-conferences/usetda-2018/.

${ }^{11}$ Conferências em: https://www.beilstein-institut.de/en/symposia/open-science.
} 
Nesse sentido, a Ciência Aberta, conhecida como Open Science torna-se elemento central do publicar no ciclo das pesquisas (fazer técnico e científico); paralelamente, o acesso aberto está inserido na sociedade global e ganha força na agenda governamental, instituições e patrocinadores de pesquisa. Os repositórios são ferramentas que vêm ganhando espaço neste fazer científico direcionado para o acesso, lembrando-se que o movimento open visa o uso de recursos gratuitos para que não hajam 'amarras' orçamentárias que interfiram no acesso da informação a ser disponibilizada.

\section{REPOSITÓRIOS E O ACESSO ABERTO: CASOS E APLICAÇÕES}

Entre os diversos elementos que norteiam o acesso à informação em um repositório estão as diretrizes regulamentadoras, chamadas de políticas; elas são definidas pela instituição como: acesso, arquivamento, uso e liberação de dados. E o uso de softwares empregados neste ambiente são informações relevantes quando se trata de acesso à informação nos moldes do open access.

Algumas estruturas foram desenvolvidas a fim de dar suporte e legitimar o movimento do acesso aberto no mundo todo. Essas estruturas têm participação de uma quantidade representativa de países e organismos internacionais, além de diversos movimentos em prol do acesso aberto; esses movimentos criam regulamentos, discutem práticas e legalidade de sistemas de Open Access, estimulam internacionalmente a adesão de novos países, organizam palestras, publicações e estudos que analisam a importância, benefícios e eficácia, não só do acesso, mas também da aplicação desse tipo de sistema em todo o mundo.

Para elucidar melhor, apresentam-se alguns organismos importantes que levantam essa bandeira em nível nacional e internacional:

a) Global Open Access Portal - GOAP - UNESCO. Reúne informações sobre os fatores críticos de sucesso para a implementação efetiva do Open Access; apresenta os pontos fortes e as oportunidades de cada país para futuros desenvolvimentos; aponta onde os mandatos para depósitos institucionais e organizações de financiamento foram postos em prática; relaciona os parceiros potenciais em nível nacional e regional; apresenta organizações 
de financiamento, advocacia e apoio em todo o mundo. Destinado ao público-alvo principal, inclui representantes políticos, defensores e delegados de organizações nacionais, regionais e não governamentais (ONG'S), bem como membros da comunidade de acesso aberto. O portal pretende ser o primeiro destino para quem procura informação sobre o acesso aberto: conhecimento relevante por país sobre o status do acesso aberto; organizações-chave envolvidas no open access nos estados-membros; áreas de enfoque temáticas de acesso aberto; publicações importantes sobre acesso aberto; avaliação crítica das principais barreiras ao acesso aberto em cada país; mandatos de financiamento e depósito; e links para iniciativas de acesso aberto no mundo;

b) Directoryof Open Access Scholarly Resources - ROAD. Trata-se de um serviço oferecido pelo Centro Internacional ISSN $^{12}$ com o apoio do Setor de Comunicação e Informação da UNESCO. Fornece acesso livre a um subconjunto do Registro ISSN, com 2.652.371 milhões de registros bibliográficos disponíveis. Os propósitos principais são: fornecer um ponto de acesso único para diferentes tipos de recursos acadêmicos on-line publicados em todo o mundo e livremente disponíveis; dar informações sobre a qualidade e proeminência dos recursos de open access, ou pelo menos os critérios que eles atendem, indicando por quais serviços ou indicadores os periódicos estão cobertos; apresentar uma visão geral da produção acadêmica de acesso aberto em todo o mundo (por exemplo, para fins estatísticos); demonstrar novas maneiras de usar o ISSN para compilar informações de várias fontes;

c) Directoryof Open Access Books. Lançado em 2012, no Reino Unido, o DOAB é um diretório de livros de acesso livre que fornece metadados sobre as monografias que receberam avaliação editorial. Conta (até 10 de agosto de 2018) com 12.729 livros de 280 editoras. Em 2015 recebeu o 'IFLA/Brill Open Access award' criado para reconhecer iniciativas que facilitam ou promovem o acesso aberto de monografias acadêmicas na área de humanidades e ciências sociais. O júri reconheceu o projeto como valioso e apontou que a iniciativa seria o ponto central na infraestrutura global para a publicação de livros em acesso aberto, em diversas áreas;

\footnotetext{
${ }^{12}$ Ver mais em: http://www.issn.org/en/understanding-the-issn/the-issn-international-register/.
} 
d) SciELO livros. Lançado em 30 de março de 2012, possibilita o acesso de 1.011 títulos, sendo 655 de acesso aberto; cerca de 8.691 capítulos de acesso aberto de mais de 3.539 autores (até agosto de 2018). A rede SciELO Livros visa a publicação online de coleções nacionais e temáticas de livros acadêmicos com o objetivo de maximizar a visibilidade, acessibilidade, uso e impacto das pesquisas, ensaios e estudos. Os livros SciELO são indexados nos serviços internacionais de busca de livros (Discovery Services) que apoiam as buscas de conteúdos nas bibliotecas acadêmicas e estão disponíveis nas principais livrarias e lojas online de acesso aberto e venda de livros. São também disponibilizados para intercâmbio e acesso automatizado segundo os principais formatos e protocolos de intercâmbio;

e) Arxiv.org. O projeto é uma importante iniciativa de preservação digital de conteúdo da web. Foi fundado 1991, é financiado e mantido pela comunidade e pela Cornell University. Disponibiliza o acesso aberto a 1.619 .029 documentos digitais nas áreas de: Física, Matemática, Ciência da Computação, Biologia Quantitativa, Finança quantitativa, Estatísticas, Engenharia Elétrica e Ciência de Sistemas, Economia;

f) Ranking Web of Repositorie. É uma iniciativa do Laboratório de Cybermetria, afiliado ao Conselho Superior de Investigações Científicas (CSIC) da Espanha. O projeto iniciou em 2006, ranqueando os repositórios desse país e se estendeu à esfera global (RANKING WEB OF REPOSITORIES, 2018). No ranking geral da $7^{\mathrm{a}}$ edição, de julho de 2019, entre o top 50, o Brasil se destaca com oito repositórios que apresentam as maiores taxas de documentos disponíveis para o acesso:

$3^{\circ}$ - Repositório Digital Universidade Federal do Rio Grande do Sul LUME,

$10^{\circ}$ - Universidade de São Paulo Biblioteca Digital de Teses e Dissertações,

$12^{\circ}$ - Repositório Alice Acesso Aberto à Informação Científica Embrapa,

$14^{\circ}$ - Repositório Institucional da Universidade Estadual Paulista Júlio de Mesquita Filho,

$15^{\circ}$ - Repositório Digital Fundação Getúlio Vargas,

$18^{\circ}$ - Repositório da Produção Científica e Intelectual da Universidade de Campinas,

$20^{\circ}$ - Repositório Institucional Universidade Federal de Santa Catarina, 
$22^{\circ}$ - Universidade Federal de São Paulo. (RANKING WEB OF REPOSITORIES, 2019);

g) Registry of Open Access Repositories - ROAR. Regista os repositórios de acesso aberto e possibilita identificar ano de criação, instituições a qual pertencem, software utilizado e o quantitativo do acervo de cada um. Constata-se que existem $3.975^{13}$ repositórios de 133 países cadastrados no ROAR. Destes, 1.834 utilizam o software Dspace, 655 o Eprints, 456 o Bepress (Berkeley Electronic Press), 90 instituições usam o OPUS (Open Publications System), os demais 940 repositórios utilizam outros softwares menos difundidos e conhecidos. A distribuição dos 3.975 por continente é de: África (147), Ásia (832), Europa (1556), North América (943), Oceania (98), South América (399), conforme dados obtidos em agosto de 2018. Verificou-se no cadastro do ROAR, em agosto de 2018, quais eram os softwares mais utilizados e os países que concentravam maior número de repositórios cadastrados no sistema; os dados podem ser conferidos na tabela 1 .

Tabela 1 - Softwares mais utilizados para repositórios, cadastrados no ROAR

\begin{tabular}{l|c|c|c|c|c}
\hline \multirow{2}{*}{ País } & \multicolumn{5}{c}{ Software mais utilizados } \\
\cline { 2 - 6 } & $\begin{array}{l}\text { Bepress } \\
(456)\end{array}$ & $\begin{array}{l}\text { Dspace } \\
(1.834)\end{array}$ & EPrints (655) & $\begin{array}{l}\text { OPUS } \\
(90)\end{array}$ & OUTROS \\
\hline $\begin{array}{l}\text { Estados Unidos } \\
(779)^{14}\end{array}$ & 360 & 151 & 62 & 2 & 204 \\
\hline Reino Unido (239) $^{15}$ & 3 & 52 & 120 & - & 64 \\
\hline Alemanha (232) & - & 19 & 26 & 79 & 108 \\
\hline${\text { Japão }(187)^{17}}^{\text {Brasil }(153)^{18}}$ & - & 105 & 6 & - & 76 \\
\hline Indonésia $(124)^{19}$ & - & 99 & 2 & - & 52 \\
\hline Índia $(114)^{20}$ & - & 16 & 89 & - & 19 \\
\hline
\end{tabular}

Fonte: Elaborado pelas autoras com base nos dados do ROAR (2018).

Percebe-se nos dados levantados no ROAR que os softwares Dspace e Eprint são utilizados por todos os sete países com maior número de repositórios cadastrados na base; já o

\footnotetext{
13 Ver a lista completa no ROAR: http://roar.eprints.org/view/geoname/.

${ }^{14}$ Estados Unidos: http://roar.eprints.org/view/geoname/geoname=5F2=5FUS.html.

15 Reino Unido: http://roar.eprints.org/view/geoname/geoname=5F2=5FGB.html.

16 Alemanha: http://roar.eprints.org/view/geoname/geoname=5F2=5FDE.html.

17 Japan: http://roar.eprints.org/view/geoname/geoname=5F2=5FJP.html.

${ }^{18}$ Brasil: http://roar.eprints.org/view/geoname/geoname=5F2=5FBR.html.

${ }^{19}$ Indonésia: http://roar.eprints.org/view/geoname/geoname=5F2=5FID.html.

20 Índia: http://roar.eprints.org/view/geoname/geoname=5F2=5FIN.html.
} 
Bepress e OPUS são aplicados em apenas dois países. Cabe salientar que alguns repositórios foram instalados, registrados e depois abandonados, seja por links com problemas de acesso, ou por não estarem povoados. É o caso dos dois repositórios que utilizam o software EPrints do Brasil. Observa-se o uso e a aplicação deste instrumento, em sua maioria, por instituições de ensino e pesquisas de nível superior.

A Library Publishing Coalition (2015) fez um estudo sobre o uso e aplicação de ferramentas como fontes de informação. O relatório menciona que os entrevistados usam uma variedade de fontes abertas, comerciais e locais, incluindo OJS (43\%) e Bepress (41\%), seguido por DSpace (29\%), software desenvolvido localmente (23\%), WordPress (23\%), CONTENTdm (21\%), Fedora (15\%) e o OCS, EPrints, Islandora, Hydra, OMS, Scalar e DPubS (cada um com menos de 10\%); o altruísmo do movimento do acesso aberto tem impactado em vários segmentos da sociedade, e esse é um dos exemplos.

O governo brasileiro embarcou neste movimento, pensando na representação e acesso dos objetos de aprendizagem, desenvolveu o padrão para metadados por meio da Multiplataforma - OBAA (2018), um tipo de repositório que utilizam software DSpace para integrar os ambientes informacionais de objetos digitais de aprendizagem de acesso aberto do país, ainda em fase de implementação;

h) Directoryof Open Access Repositories - OpenDOAR. O diretório relaciona mais de 3.290 repositórios de instituições acadêmicas e de pesquisa, possibilita a busca por categorias de assuntos específicos, países, tipos de documentos, idiomas, softwares, e permite visualizar em gráficos os tipos de documentos. Apresenta os repositórios por temáticas e os agrupamentos de assuntos contemplam as áreas do conhecimento: Multidisciplinar, Artes e Humanidades, Ciências Sociais, Ciências, Engenharia e Tecnologia e Ciências da saúde. Observou-se no OpenDOAR ${ }^{21}$ que é frequente o uso de repositórios para a postagens de revistas/publicação científica, principalmente as que usam o software livre OJS;

i) Open Journal System - OJS. Desenvolvido no Canadá pela PKP-Public Knowledge Project (2018a) da Universidade de British Columbia, é amplamente utilizado,

\footnotetext{
${ }^{21}$ Veja a aplicação da ferramenta repositório no ranking de tipologias documentais, em: http://www.opendoar.org/onechart. php?cID=\&ctID=\&rtID=\&clID=\&IID=\&potID=\&rSoftWareName=\&search=\&groupby=ct.ctDefinition\&orderby=Tally $\%$ 20DESC\&charttype=bar\&width=600\&caption=Content $\% 20$ Types $\% 20$ in $\% 20$ OpenDOAR $\% 20$ Repositories $\% 20$ \%20Worldwide.
} 
principalmente na América Latina; ambos são dois sistemas de open access e softwares livres. O OJS funciona de maneira integrada via internet, facilita todo processo de publicação científica desde a submissão de um artigo, a seleção de avaliadores (revisores), auxilia na visibilidade das atividades, encaminhamento de mensagens disparadas conforme programação e gerência, prazos para entrega das correções até mesmo à sua publicação e indexação (plugins). É mais um sistema direcionado para o acesso; a PKP levanta a bandeira da publicação científica acessível para todos. Conforme registros estatísticos do Public Project Knowledege - PKP (2018b), o software Open Journal System é utilizado por cerca de dez mil periódicos para publicar seu acervo.

No estudo de Alperin, Babini e Fischman (2014) estima-se que 4.000 revistas científicas de regiões em desenvolvimento utilizam o OJS; e que as três maiores instituições não comerciais que apoiam iniciativas no acesso aberto de revistas científicas são: LATINDEX, SciELO e RedALyC.

A pesquisa realizada por Shintaku, Brito e Carvalho Neto (2014, p.114) indica a quantidade de revistas registradas em 123 portais no Brasil; destaca o Portal de Periódicos da Universidade de São Paulo (USP) com 108 periódicos; seguido do Portal de Periódicos Científicos da Universidade Federal do Rio Grande do Sul (UFGRS), que hospeda 68 revistas (sendo 52 revistas ativas e 16 inativas). Observa-se nessa pesquisa que algumas instituições utilizam o ambiente "Portal de Periódicos" para o registro de anais de eventos publicados e, até mesmo, como memória no sentido de incluir as revistas inativas para garantir a acessibilidade contínua ao acervo. Entre as vantagens do acesso aberto está a visibilidade internacional e as citações das revistas com menor custo em sua produção. No entanto, para que haja melhores resultados internacionais das publicações científicas, é necessário que o Estado assuma o papel em promover a pesquisa nacional (MORALES MORANTE, 2016).

O uso do software OJS para publicar conteúdo pode ser eclético, pois a Universidade FUMEC utiliza-o para publicar e divulgar os projetos, dissertações e teses, Programa de PósGraduação em Sistemas de Informação e Gestão do Conhecimento da Faculdade de Ciências Empresariais - FACE;

j) Directoryof Open Access Journal - DOAJ. O diretório foi criado em 2003 pela Universidade de Lund, Suécia, iniciou o acervo com 300 revistas de acesso aberto, atualmente 
indexa e oferece acesso à cerca de 13.939 revistas, 4.427 .594 artigos de 130 países, em quase todas as áreas de conhecimento;

k) Registry of Open Access Repository Mandates and Policies - ROARMAP. É um portal de registro internacional, utilizado para mensurar o aumento do uso de repositórios voltados para o acesso aberto que detém políticas definidas. Apresenta em seus registros cerca 941 políticas de auto arquivamento depositadas no sistema, sendo: organizações de pesquisa 716; fundadores - 83; subunidades e organizações de pesquisa - 75; fundadores e organizações de pesquisa - 56; e outras múltiplas organizações de investigação - 11 documentos (ROARMAP, 2018a).

Imagem 1 - Políticas mandatárias brasileiras cadastradas no ROARMAP

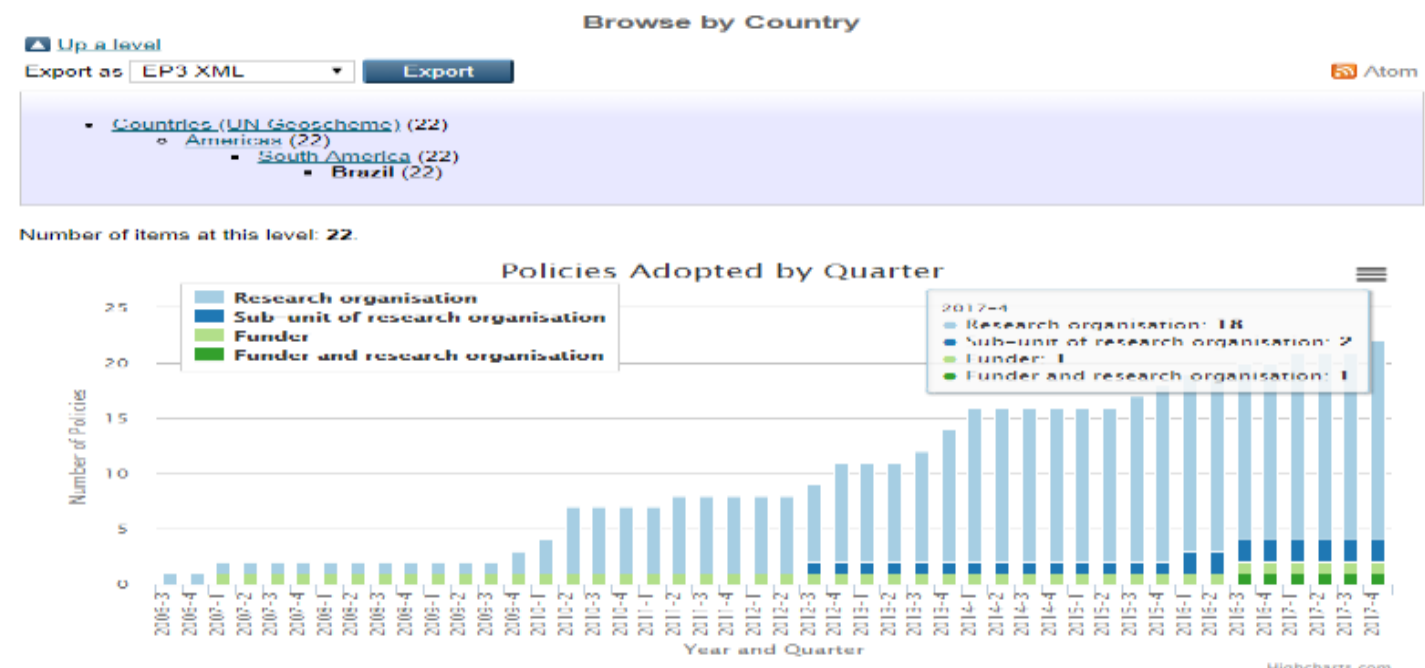

Fonte: Gráfico obtidos do ROARMAP (2018b).

Conforme os dados no ROARMAP (2018b), existem 22 instituições brasileiras depositantes de políticas mandatárias institucionais, 18 organizações de pesquisa, 2 subunidades de organização de pesquisa, 1 fundador e, 1 fundador e organização de pesquisa: Câmara dos Deputados (Brazil House of Representatives); Escola Nacional de Saúde Pública Sergio Arouca/Fiocruz (ENSP); Fundação João Pinheiro (FJP); Fundação Oswaldo Cruz (FIOCRUZ); Repositório Institucional UNIFESP (SP); Unidade Acadêmica de Geografia (UFCG/PB); Universidade Aberta do Sistema Único de Saúde (UMA-SUS); Universidade Federal da Bahia (UFBA); Universidade Federal da Integração Latino-Americana (UNILA); 
Universidade de Goiás (UFG); Universidade Federal de Lavras (UFLA); Universidade Federal de Ouro Preto (UFOP); Universidade Federal de Sergipe (UFS); Universidade Federal do Ceará (UFC); Universidade Federal do Pampa (UNIPAMPA/RS); Universidade Federal do Pará (UFPA); Universidade Federal do Recôncavo da Bahia (UFRB); Universidade Federal do Rio Grande (FURG); Universidade Federal do Rio Grande do Norte (UFRN); Universidade Tecnológica Federal do Paraná (UTFPR); Universidade Tecnológica Federal do Paraná (UTFPR); Universidade de Brasília (UnB); Universidade de São Paulo (USP);

Cabe destacar que as políticas mandatárias são instrumentos importantes para regulamentar o uso e acesso do sistema e do acervo. O cenário legislativo do qual os repositórios enredam suas aplicações são variados, dependem de políticas de informação nacional e institucional, de acesso, de inserção, de autoria, padrão, preservação, entre outras, as quais devem respeitar a legislação vigente, tanto de direitos autorais Lei n. 9.610, de 1998 quanto a de acesso à informação, Lei n. 12.527 de 2011, no caso do Brasil;

1) Dataverse. Trata-se de exemplo de sistema de repositório que utiliza a aplicação de código aberto; é bem aceito na Europa, desenvolvido em 2006 pela Universidade de Harvard. A finalidade é partilhar, preservar, explorar e analisar dados de pesquisa. O programa facilita a recolha de dados e os torna disponíveis para os outros Dataverses. $\quad$ O repositório de Harvard utiliza o sistema Dataverse interligado a outras 33instituições, sendo 2.866 documentos compartilhados. Tem disponível em seu acervo diferentes conjuntos informacionais, entre eles 402.054 documentos e 4.066.866 downloads (HARVARD, 2018).

Das instituições que utilizam o Dataverses várias são reconhecidas mundialmente; entre elas está a rede Cariniana - Rede Brasileira de Preservação Digital do IBICT ${ }^{22}$. Com poucos objetos compartilhados e disponíveis, faz parte de um projeto piloto que visa disponibilizar, até 2060, informação científica e tecnologia dos serviços de pesquisa e informação de Brasília.

O uso de repositórios como ferramenta para a disseminação da informação vem de encontro com o movimento Open, pois, como foi mencionado no exemplo, muitas instituições e organismos disponibilizam em repositórios seus dados de pesquisas, documentos, normas, políticas e suas publicações. Uma das bandeiras do projeto Horizonte 2020 é que todos os

\footnotetext{
${ }^{22}$ Ver mais em: https://repositoriopesquisas.ibict.br/.
} 
dados de pesquisa sejam depositados em repositórios de acesso aberto, colaborando para a promoção da ciência no modelo Open Science (COUNCIL OF THE EUROPEAN UNION, 2016).

\section{METODOLOGIA}

Está pesquisa, de caráter descritivo, utilizou o levantamento bibliográfico na coleta de dados pertinentes à reflexão do tema (RAMPAZZO, 2013) e a descrição dos resultados para a análise dos dados obtidos das pesquisas (CRESWEL, 2010).

Para o presente estudo foram feitos levantamentos na web, em bases de dados, repositórios e diretórios a fim de elucidar o cenário de aplicação de repositórios de acesso aberto. Como primeiro momento, buscou-se exemplos de instrumentos, declarações e eventos recentes sobre o acesso aberto, considerados importantes para a reflexão do tema.

No segundo momento foi realizado um outro levantamento para exemplificar organismos internacionais que figuram o movimento do acesso aberto. Também buscou-se exemplos de aplicações de repositórios brasileiros de acesso aberto.

Ao passo que os repositórios e diretórios de mapeamentos foram trazidos para a exemplificação, sentiu-se a necessidade de verificar a situação internacional e compará-la com a nacional. Diante desta perspectiva, foram empregados os dados do ROAR sobre os registros de softwares e repositórios, observando-se quais softwares e países eram mais representativos na plataforma. O mesmo aconteceu com o ROARMAP, no qual se buscou apresentar as instituições brasileiras com políticas mandatárias, obtendo uma lista de 22 organismos de pesquisa, ensino e administração.

E, no terceiro momento, visou-se conhecer o panorama das pesquisas científicas brasileiras sobre repositórios de acesso aberto, disponíveis na BDTD-Biblioteca Digital Brasileira de Teses e Dissertações e, no SciELO. Tais dados foram coletados em 25 de julho de 2018.

A escolha das bases se deu devido a alguns requisitos: o interesse em conhecer o cenário da pesquisa sobre o tema no Brasil, e também, saber como estavam as pesquisas brasileiras sobre o tema em instituição de ensino superior; por esse motivo optou-se pela 
escolha da BDTD; outro requisito era que a base deveria ser do movimento do acesso aberto, assim, optou-se pelo SciELO.

Na coleta feita na BDTD (2018a; 2018b) foram utilizados os seguintes termos de busca: Repositório + Acesso Aberto, no campo assunto, sem aspas, recuperando 19 pesquisas; e "Acesso Aberto" + Repositório, na opção todos os campos, com aspas nos termos acesso aberto, recuperando 96 estudos. A soma das duas buscas foi de 115 trabalhos, dos quais 31 caracterizaram a amostra do estudo que configurou um recorte de 2006-2018. Cabe ressaltar que foram testadas várias combinações de termos para a busca; os mais representativos foram esses, pois não restringiram muito e nem pouco o sistema de busca da base.

A coleta feita no SciELO (2018) foi estruturada da seguinte maneira: a busca, em campo geral, empregou o termo em inglês, "Open Access + Repositories", recuperando 49 artigos, contendo textos em inglês, espanhol e português; destes, 25 representam o assunto. Optou-se pelo emprego do termo em inglês por não se obter resultados relevantes quando utilizado o termo "Repositório + Acesso Aberto" em português, que mostrou apenas 2 artigos que tratavam do assunto.

A seleção das pesquisas se deu por meio do método analítico de ocorrência, o qual emprega a seleção de textos que tenham ocorrência dos termos de busca: Repositório + Acesso Aberto (FLICK, 2009). Para ter certeza de que as pesquisas realmente tratavam do assunto, foi realizada a leitura dos resumos e palavras-chave de todos os textos recuperados nas duas bases.

Os dados apresentam pontos de reflexão a respeito do perfil das pesquisas. Não se tinha a intenção de quantificar ou qualificar os estudos analisados, mas sim conhecer o perfil das pesquisas, quais vieses e ações são aplicados nos estudos sobre repositórios.

\section{APRESENTAÇÃO DOS RESULTADOS E ANÁLISES DAS PESQUISAS SOBRE REPOSITÓRIOS DE ACESSO ABERTO NO BRASIL}

Para saber como está a produção de pesquisas sobre repositórios de acesso aberto no Brasil, buscou-se conhecer o cenário em duas bases de open access: na BDTD e na rede SciELO.

Ressalta-se que a BDTD é uma base de acesso aberto do Instituto Brasileiro de Informação em Ciência e Tecnologia (IBICT), exclusiva para a divulgação da produção 
científica de teses e dissertações produzidas no Brasil. Seu acervo atualmente é composto por 528.963 documentos, destes 157.279 são teses, 371.685 dissertações do total de 109 instituições de pesquisa. Atende à política nacional de publicação e acesso aberto da produção científica de todas as teses e dissertações produzidas no país, em instituições com Programas de Pós-Graduação regulamentados pelo MEC, sejam elas com fomento ou não de verba para a pesquisa.

Na pesquisa feita na BDTD (2018a; 2018b) obteve-se, com a soma das duas buscas, o total de 115 trabalhos, destes 88 são dissertações e 27 teses. No quadro 1 seguem os dados detalhados.

Quadro 1- Pesquisas sobre Repositório de acesso aberto publicadas na BDTD

\begin{tabular}{|c|c|c|c|c|}
\hline INST. & TIPO & AUTOR & TÍTULO & $\begin{array}{l}\mathbf{A N} \\
\mathbf{O}\end{array}$ \\
\hline \multirow{7}{*}{ UNB } & \multirow{5}{*}{$\begin{array}{l}\text { Disser } \\
\text { t. }\end{array}$} & $\begin{array}{l}\text { Larissa Melo } \\
\text { Bezerra de } \\
\text { Oliveira }\end{array}$ & $\begin{array}{l}\text { Elementos estruturantes para a elaboração de } \\
\text { política de direito autoral para repositórios } \\
\text { institucionais de acesso aberto. }\end{array}$ & 2016 \\
\hline & & $\begin{array}{l}\text { Luísa Chaves } \\
\text { Café }\end{array}$ & $\begin{array}{l}\text { Avaliação da usabilidade na interação e } \\
\text { recuperação da informação dos usuários pós- } \\
\text { graduandos no repositório institucional da } \\
\text { universidade de Brasília. }\end{array}$ & 2016 \\
\hline & & $\begin{array}{l}\text { Julio Francisco } \\
\text { SantillánAldana }\end{array}$ & $\begin{array}{l}\text { Modelos de negócio dos periódicos científicos } \\
\text { de acesso aberto na América Latina e Caribe. }\end{array}$ & 2014 \\
\hline & & $\begin{array}{l}\text { Ernani Rufino dos } \\
\text { Santos Junior }\end{array}$ & $\begin{array}{l}\text { Repositórios institucionais de acesso livre no } \\
\text { Brasil: estudo Delfos }\end{array}$ & 2010 \\
\hline & & $\begin{array}{l}\text { Fernanda de } \\
\text { Souza Monteiro }\end{array}$ & $\begin{array}{l}\text { Organização da informação em repositórios } \\
\text { digitais institucionais com ênfase na descrição } \\
\text { física e descrição temática }\end{array}$ & 2008 \\
\hline & \multirow[t]{2}{*}{ Tese } & $\begin{array}{l}\text { Marília Augusta } \\
\text { de Freitas }\end{array}$ & $\begin{array}{l}\text { Diretrizes para o depósito da produção } \\
\text { científica em repositórios institucionais. }\end{array}$ & 2016 \\
\hline & & José D. Freire & $\begin{array}{l}\text { CNPQ e o acesso aberto à informação } \\
\text { científica }\end{array}$ & 2011 \\
\hline \multirow{4}{*}{$\begin{array}{l}\text { UFSCA } \\
\mathrm{R}\end{array}$} & \multirow{4}{*}{$\begin{array}{l}\text { Disser } \\
\text { t. }\end{array}$} & $\begin{array}{l}\text { José Eduardo dos } \\
\text { Reis }\end{array}$ & $\begin{array}{l}\text { Incipiência da disponibilidade de indicadores } \\
\text { bibliométricos e altmétricos nos repositórios } \\
\text { institucionais brasileiros }\end{array}$ & 2017 \\
\hline & & $\begin{array}{l}\text { Izabel da Mota } \\
\text { Franco }\end{array}$ & $\begin{array}{l}\text { Repositórios digitais institucionais: um viés } \\
\text { pela lei de acesso à informação. }\end{array}$ & 2015 \\
\hline & & $\begin{array}{l}\text { Kamilla Vinha } \\
\text { Carlos de Godoy }\end{array}$ & $\begin{array}{l}\text { Identificação de diretrizes para elaboração de } \\
\text { política de acesso aberto aos conteúdos } \\
\text { educacionais disponibilizados em repositórios } \\
\text { digitais no contexto da educação a distância. }\end{array}$ & 2015 \\
\hline & & $\begin{array}{l}\text { Mesailde Souza } \\
\text { de Oliveira } \\
\text { Matias }\end{array}$ & $\begin{array}{l}\text { Base referencial para o povoamento de } \\
\text { repositórios institucionais: coleta automatizada } \\
\text { de metadados da Plataforma Lattes }\end{array}$ & 2015 \\
\hline
\end{tabular}




\begin{tabular}{|c|c|c|c|c|}
\hline \multirow[t]{2}{*}{ UFPB } & \multirow[t]{2}{*}{$\begin{array}{l}\text { Disser } \\
\text { t. }\end{array}$} & $\begin{array}{l}\text { Vânia Maria } \\
\text { Ramos da Silva }\end{array}$ & $\begin{array}{l}\text { A representação temática da informação em } \\
\text { TCC do curso de direito da UFPB: análise do } \\
\text { vocabulário controlado no repositório } \\
\text { eletrônico institucional da UFPB. }\end{array}$ & 2013 \\
\hline & & $\begin{array}{l}\text { Rosilene F. } \\
\text { Machado }\end{array}$ & $\begin{array}{l}\text { Repositório eletrônico institucional: } \\
\text { preservando o conhecimento através de } \\
\text { tecnologias da inteligência. }\end{array}$ & 2012 \\
\hline \multirow[t]{2}{*}{ USP } & $\begin{array}{l}\text { Disser } \\
\text { t. }\end{array}$ & $\begin{array}{l}\text { Murilo } \\
\text { GleysonGazzola }\end{array}$ & $\begin{array}{l}\text { Uma arquitetura para mecanismos de buscas na } \\
\text { web usando integração de esquemas e padrões } \\
\text { de metadados heterogêneos de recursos } \\
\text { educacionais abertos em repositórios dispersos. }\end{array}$ & 2015 \\
\hline & Tese & $\begin{array}{l}\text { Simone da Rocha } \\
\text { Weitzel }\end{array}$ & $\begin{array}{l}\text { Os repositórios de E-Prints como nova forma } \\
\text { de organização da produção científica: o caso } \\
\text { da área das ciências da comunicação no Brasil. }\end{array}$ & 2006 \\
\hline \multirow[t]{3}{*}{ UFBA } & \multirow{2}{*}{$\begin{array}{l}\text { Disser } \\
\text { t. }\end{array}$} & $\begin{array}{l}\text { Anilza Rita de } \\
\text { Souza Gomes }\end{array}$ & $\begin{array}{l}\text { Práticas de disponibilização da produção } \\
\text { científica da UFBA: contribuição à política } \\
\text { institucional de acesso aberto. }\end{array}$ & 2017 \\
\hline & & $\begin{array}{l}\text { Rodrigo França } \\
\text { Meirelles }\end{array}$ & $\begin{array}{l}\text { Gestão do processo editorial eletrônico baseado } \\
\text { no modelo acesso aberto: estudo em periódicos } \\
\text { científicos da Universidade Federal da Bahia - } \\
\text { UFBA. }\end{array}$ & 2009 \\
\hline & Tese & $\begin{array}{l}\text { Flávia Goulart } \\
\text { Mota Garcia Rosa }\end{array}$ & $\begin{array}{l}\text { A disseminação da produção científica da } \\
\text { Universidade Federal da Bahia através da } \\
\text { implantação do seu repositório institucional: } \\
\text { uma política de acesso aberto. }\end{array}$ & 2011 \\
\hline \multirow[t]{2}{*}{ IBICT } & \multirow[t]{2}{*}{$\begin{array}{l}\text { Disser } \\
\text { t. }\end{array}$} & $\begin{array}{l}\text { Fatima Cristina } \\
\text { Lopes dos Santos }\end{array}$ & $\begin{array}{l}\text { Coerência na representação temática de artigos } \\
\text { científicos indexados no repositório de saúde } \\
\text { pública da Fundação Oswaldo Cruz }\end{array}$ & 2017 \\
\hline & & $\begin{array}{l}\text { Aline Vieira do } \\
\text { Nascimento }\end{array}$ & $\begin{array}{l}\text { Repositórios digitais: identificando fatores de } \\
\text { sucesso para as bibliotecas digitais e } \\
\text { repositórios institucionais. }\end{array}$ & 2014 \\
\hline UFLA & $\begin{array}{l}\text { Disser } \\
\text { t. }\end{array}$ & $\begin{array}{l}\text { Simone Assis } \\
\text { Medeiros }\end{array}$ & $\begin{array}{l}\text { Política pública de acesso aberto à produção } \\
\text { científica: o caso do repositório institucional da } \\
\text { Universidade Federal de Lavras. }\end{array}$ & 2013 \\
\hline UFRGS & $\begin{array}{l}\text { Disser } \\
\text { t. }\end{array}$ & $\begin{array}{l}\text { Caterina Marta } \\
\text { Groposo Pavão }\end{array}$ & $\begin{array}{l}\text { Contribuição dos repositórios institucionais à } \\
\text { comunicação científica: um estudo na } \\
\text { Universidade Federal do Rio Grande do Sul. }\end{array}$ & 2010 \\
\hline UFSM & $\begin{array}{l}\text { Disser } \\
\text { t. }\end{array}$ & $\begin{array}{l}\text { Luciana Corrêa } \\
\text { Vieira }\end{array}$ & $\begin{array}{l}\text { Organização e disseminação da produção } \\
\text { científica dos docentes do CCSH/UFSM em } \\
\text { um repositório digital. }\end{array}$ & 2013 \\
\hline UTFPR & $\begin{array}{l}\text { Disser } \\
\text { t. }\end{array}$ & $\begin{array}{l}\text { Flaviani Andrade } \\
\text { de Lara }\end{array}$ & $\begin{array}{l}\text { Acesso aberto ao conhecimento científico e } \\
\text { acessibilidade na percepção da pessoa surda. }\end{array}$ & 2014 \\
\hline UFPE & $\begin{array}{l}\text { Disser } \\
\text { t. }\end{array}$ & $\begin{array}{l}\text { Rossana de Paula } \\
\text { Junqueira }\end{array}$ & $\begin{array}{l}\text { RECOBA: um ambiente para publicação e } \\
\text { compartilhamento de objetos de aprendizagem } \\
\text { no formato aberto e fragmentado. }\end{array}$ & 2015 \\
\hline UFSM & $\begin{array}{l}\text { Disser } \\
\text { t. }\end{array}$ & $\begin{array}{l}\text { Sérgio Renato } \\
\text { Lampert }\end{array}$ & $\begin{array}{l}\text { Repositório digital para o patrimônio } \\
\text { arquivístico documental: subsídio para acesso e } \\
\text { preservação do diário de classe. }\end{array}$ & 2013 \\
\hline UFRN & $\begin{array}{l}\text { Disser } \\
\text { t. }\end{array}$ & $\begin{array}{l}\text { Clediane de } \\
\text { Araújo Guedes } \\
\text { Marques }\end{array}$ & $\begin{array}{l}\text { Repositório Institucional da UFRN e Sistema } \\
\text { Integrado de Gestão de Atividades Acadêmicas } \\
\text { (SIGAA): proposta de interoperabilidade }\end{array}$ & 2017 \\
\hline
\end{tabular}




\begin{tabular}{|l|l|l|l|l|}
\hline UFVJM & $\begin{array}{l}\text { Disser } \\
\text { t. }\end{array}$ & $\begin{array}{l}\text { Felipe Lopes } \\
\text { Alves }\end{array}$ & $\begin{array}{l}\text { Diretrizes para o desenvolvimento de uma } \\
\text { política de informação: o povoamento do } \\
\text { repositório institucional da Universidade } \\
\text { Federal dos Vales do Jequitinhonha e Mucuri }\end{array}$ & 2017 \\
\hline $\begin{array}{l}\text { FIOCR } \\
\text { UZ }\end{array}$ & $\begin{array}{l}\text { Disser } \\
\text { t. }\end{array}$ & $\begin{array}{l}\text { Maria da } \\
\text { Conceição R. de } \\
\text { Carvalho }\end{array}$ & $\begin{array}{l}\text { O Reuso da informação técnico-científica a } \\
\text { partir de um repositório institucional (RI): um } \\
\text { estudo exploratório }\end{array}$ & 2011 \\
\hline UNESP & Tese & $\begin{array}{l}\text { Alex Silva } \\
\text { Rodrigues }\end{array}$ & $\begin{array}{l}\text { Diretrizes de funcionamento para repositórios: } \\
\text { caminhos para os institutos federais de } \\
\text { educação, ciência e tecnologia }\end{array}$ & 2018 \\
\hline UFC & Tese & $\begin{array}{l}\text { Nirlange Pessoa } \\
\text { de Queiroz }\end{array}$ & $\begin{array}{l}\text { Avaliação do Repositório Institucional da } \\
\text { Universidade Federal do Ceará na perspectiva } \\
\text { da difusão e do acesso à produção científica }\end{array}$ & 2015 \\
\hline
\end{tabular}

Fonte: Dados da pesquisa, coletados na BDTD (15 jul. 2018).

Das 115 pesquisas recuperadas na BDTD que versam sobre repositórios ou acesso aberto, com foco em vários temas e subtemas, apenas 31 são pesquisas com abordagem específicas sobre repositórios de acesso aberto.

Os anos com maior produção sobre o assunto foram: 2013 (4), 2015 (6), 2017 (5); os anos de 2011, 2014 e 2016 tiveram (3) estudos cada, os demais 1 e 2. Observa-se o aumento significativo nos anos mais recentes, sendo publicadas 15 pesquisas. A instituição que mais pesquisou sobre o assunto foi a Universidade de Brasília, com a produção de 5 dissertações e 2 teses.

Para contrastar os dados obtidos na BDTD também foi realizada uma busca na SciELO, no intuito de compreender a divulgação científica.

Lembra-se que o SciELO é uma rede informacional de iniciativa de open access para a produção científica. A rede integra os países da América Latina do Sul e do Caribe; são ao todo 16 países participantes. Contém um acervo de 1.285 periódicos, 52.356 fascículos, 745.182 artigos e 16.943 .454 citações.

Ao pesquisar no SciELO (2018) com termo "open access + repositories" em inglês, obteve-se 49 resultados, com textos em inglês, espanhol e português; destes, 25 representam o assunto, conforme pode ser observado no quadro 2 . 
Quadro 2 - Pesquisas no SciELO

\begin{tabular}{|c|c|c|c|c|}
\hline CANAL & TIPO & AUTOR & TÍTULO & ANO \\
\hline $\begin{array}{l}\text { Perspectivas em } \\
\text { Ciência da } \\
\text { Informação }\end{array}$ & $\begin{array}{l}\text { Artigo/ } \\
\text { Brasil }\end{array}$ & $\begin{array}{l}\text { Alvarez, Gonzalo } \\
\text { Rubén; Caregnato, } \\
\text { Sônia Elisa. }\end{array}$ & $\begin{array}{l}\text { Preprints na comunicação científica da } \\
\text { Física de Altas Energias: análise das } \\
\text { submissões no repositório arXiv } \\
(2010-2015)\end{array}$ & 2017 \\
\hline $\begin{array}{l}\text { Revista } \\
\text { Interamericana } \\
\text { de } \\
\text { Bibliotecología }\end{array}$ & $\begin{array}{l}\text { Artigo/ } \\
\text { Colomb } \\
\text { ia }\end{array}$ & $\begin{array}{l}\text { Rodrigues Rezende, } \\
\text { Laura Vilela; Lima } \\
\text { Torres, Denilza; } \\
\text { Cruz-Riascos, Sonia. }\end{array}$ & $\begin{array}{l}\text { Herramientas de accesoabiertoenla } \\
\text { Universidade Federal de Goiás, Brasil: } \\
\text { una prospección }\end{array}$ & 2016 \\
\hline $\begin{array}{l}\text { Revista Cubana } \\
\text { de } \\
\text { InformaciónenC } \\
\text { iencias de } \\
\text { laSalud }\end{array}$ & $\begin{array}{l}\text { Artigo/ } \\
\text { Cuba }\end{array}$ & $\begin{array}{l}\text { Molina Piñeiro, } \\
\text { Maricela; } \\
\text { MarreroSera, Eloísa } \\
\text { Felina; Puentes } \\
\text { Puente, Ángel de } \\
\text { Jesús. }\end{array}$ & $\begin{array}{l}\text { Los repositorios de accesoabierto } \\
\text { como alternativa para lavisibilidad de } \\
\text { lacienciaenlas universidades: estudio } \\
\text { de caso }\end{array}$ & 2015 \\
\hline $\begin{array}{l}\text { Revista Cubana } \\
\text { de } \\
\text { InformaciónenC } \\
\text { iencias de } \\
\text { laSalud }\end{array}$ & $\begin{array}{l}\text { Artigo/ } \\
\text { Cuba }\end{array}$ & $\begin{array}{l}\text { Cano Inclán, } \\
\text { Anisley; de Dios } \\
\text { Arias, Raiza Ana; } \\
\text { García García, } \\
\text { Ognara; Cuesta } \\
\text { Rodríguez, } \\
\text { Floriselda. }\end{array}$ & $\begin{array}{l}\text { Los repositoriosinstitucionales: } \\
\text { situaciónactual a nivel internacional, } \\
\text { latinoamericano y enCuba }\end{array}$ & 2015 \\
\hline MEDISAN & $\begin{array}{l}\text { Artigo/ } \\
\text { Cuba }\end{array}$ & $\begin{array}{l}\text { Duperet Cabrera, } \\
\text { Elaine; Pérez } \\
\text { Martínez, Denis } \\
\text { Gabriel; Cedeño } \\
\text { Rodríguez, } \\
\text { MirthaYris; Ramírez } \\
\text { Mustelier, Adrian; } \\
\text { Montoya Acosta, } \\
\text { Luis Alberto. }\end{array}$ & $\begin{array}{l}\text { Importancia de losrepositorios para } \\
\text { preservar y recuperarlainformación }\end{array}$ & 2015 \\
\hline Convergencia & $\begin{array}{l}\text { Artigo/ } \\
\text { México }\end{array}$ & $\begin{array}{l}\text { Ayala-Perdomo, Juan } \\
\text { Carlos. }\end{array}$ & $\begin{array}{l}\text { Los repositorios científicos digitales: } \\
\text { conocimiento social enla era } \\
\text { delaccesoabierto }\end{array}$ & 2015 \\
\hline $\begin{array}{l}\text { Información, } \\
\text { cultura y } \\
\text { sociedad }\end{array}$ & $\begin{array}{l}\text { Artigo/ } \\
\text { Argenti } \\
\text { na }\end{array}$ & $\begin{array}{l}\text { Bongiovani, Paola } \\
\text { C.; Guarnieri, } \\
\text { Griselda; Babini, } \\
\text { Dominique; López, } \\
\text { Fernando A. }\end{array}$ & $\begin{array}{l}\text { AccesoabiertoenlaUniversidad } \\
\text { Nacional de Rosario: Necesidades y } \\
\text { prácticas de los } \\
\text { docentes/investigadores }\end{array}$ & 2015 \\
\hline $\begin{array}{l}\text { Revista } \\
\text { Interamericana } \\
\text { de } \\
\text { Bibliotecología }\end{array}$ & $\begin{array}{l}\text { Artigo/ } \\
\text { Colomb } \\
\text { ia }\end{array}$ & $\begin{array}{l}\text { Texier, Jose; De } \\
\text { Giusti, Marisa R.; } \\
\text { Lira, Ariel J.; } \\
\text { Oviedo, Nestor; } \\
\text { Villarreal, Gonzalo } \\
\text { L. }\end{array}$ & $\begin{array}{l}\text { DSpace como herramienta para } \\
\text { unrepositorio de documentos } \\
\text { administrativos enlaUniversidad } \\
\text { Nacional Experimental delTáchira }\end{array}$ & 2013 \\
\hline $\begin{array}{l}\text { Revista Cubana } \\
\text { de } \\
\text { InformaciónenC } \\
\text { iencias de }\end{array}$ & $\begin{array}{l}\text { Artigo/ } \\
\text { Cuba }\end{array}$ & $\begin{array}{l}\text { Bongiovani, Paola; } \\
\text { Miguel, Sandra; } \\
\text { Gómez, Nancy } \\
\text { Diana. }\end{array}$ & $\begin{array}{l}\text { Accesoabierto, impacto científico y } \\
\text { laproducción científica en dos } \\
\text { universidades argentinas enel campo } \\
\text { de la medicina }\end{array}$ & 2013 \\
\hline
\end{tabular}




\begin{tabular}{|c|c|c|c|c|}
\hline laSalud & & & & \\
\hline $\begin{array}{l}\text { Motriz: Revista } \\
\text { de Educação } \\
\text { Física }\end{array}$ & $\begin{array}{l}\text { Artigo/ } \\
\text { Brasil }\end{array}$ & $\begin{array}{l}\text { Ferrari, Rodrigo } \\
\text { Duarte; Pires, } \\
\text { Giovani De Lorenzi. }\end{array}$ & $\begin{array}{l}\text { Cultura colaborativa e gestão do } \\
\text { conhecimento em esporte e lazer }\end{array}$ & 2013 \\
\hline Palabra clave & $\begin{array}{l}\text { Artigo/ } \\
\text { Argenti } \\
\text { na }\end{array}$ & $\begin{array}{l}\text { Miguel, Sandra; } \\
\text { Bongiovani, Paola; } \\
\text { Gómez, Nancy } \\
\text { Diana; Bueno de la } \\
\text { Fuente, Gema. } \\
\end{array}$ & $\begin{array}{l}\text { Situación y perspectivas } \\
\text { deldesarrollodelAccesoAbiertoen } \\
\text { Argentina }\end{array}$ & 2013 \\
\hline $\begin{array}{l}\text { Revista } \\
\text { electrónica de } \\
\text { investigación } \\
\text { educativa }\end{array}$ & $\begin{array}{l}\text { Artigo/ } \\
\text { México }\end{array}$ & $\begin{array}{l}\text { Adame Rodríguez, } \\
\text { Silvia Irene; } \\
\text { LlorénsBaez, Luis; } \\
\text { SchorrWiener, } \\
\text { Michel. } \\
\end{array}$ & $\begin{array}{l}\text { Retrospectiva de losrepositorios de } \\
\text { accesoabierto y } \\
\text { tendenciasenlasocializacióndelconocim } \\
\text { iento }\end{array}$ & 2013 \\
\hline $\begin{array}{l}\text { NutriciónHospit } \\
\text { alaria }\end{array}$ & $\begin{array}{l}\text { Artigo/ } \\
\text { Espanh } \\
\text { a }\end{array}$ & $\begin{array}{l}\text { Soares Guimarães, } \\
\text { M.a C.; Silva, C. H. } \\
\text { da; Horsth Noronha, } \\
\text { I. }\end{array}$ & $\begin{array}{l}\text { Los repositorios temáticos } \\
\text { enlaestrategia de la iniciativa Open } \\
\text { Access }\end{array}$ & 2012 \\
\hline $\begin{array}{l}\text { Revista } \\
\text { Interamericana } \\
\text { de } \\
\text { Bibliotecología }\end{array}$ & $\begin{array}{l}\text { Artigo/ } \\
\text { Colomb } \\
\text { ia }\end{array}$ & Tzoc, Elías. & $\begin{array}{l}\text { El AccesoAbiertoen América Latina: } \\
\text { Situaciónactual y expectativas }\end{array}$ & 2012 \\
\hline $\begin{array}{l}\text { Investigaciónbib } \\
\text { liotecológica }\end{array}$ & $\begin{array}{l}\text { Artigo/ } \\
\text { México }\end{array}$ & $\begin{array}{l}\text { Varela-Prado, } \\
\text { Carmen; Baiget, } \\
\text { Tomàs. } \\
\end{array}$ & $\begin{array}{l}\text { El futuro de las bibliotecas } \\
\text { académicas: incertidumbres, } \\
\text { oportunidades y retos }\end{array}$ & 2012 \\
\hline $\begin{array}{l}\text { Revista } \\
\text { Interamericana } \\
\text { de } \\
\text { Bibliotecología }\end{array}$ & $\begin{array}{l}\text { Artigo/ } \\
\text { Colomb } \\
\text { ia }\end{array}$ & $\begin{array}{l}\text { Sanllorenti, Ana } \\
\text { María; Pelaya, Lucía; } \\
\text { Williman, Martín. }\end{array}$ & $\begin{array}{l}\text { Instrumentos para lagestióndelderecho } \\
\text { de autor enrepositorios de } \\
\text { AccesoAbierto }\end{array}$ & 2011 \\
\hline $\begin{array}{l}\text { Revista } \\
\text { iberoamericana } \\
\text { de } \\
\text { cienciatecnologí } \\
\text { a y sociedad }\end{array}$ & $\begin{array}{l}\text { Artigo/ } \\
\text { Argenti } \\
\text { na }\end{array}$ & Babini, Dominique. & $\begin{array}{l}\text { Accesoabierto a laproducción } \\
\text { científica de América Latina y el } \\
\text { Caribe: } \\
\text { Identificationofmaininstitutions for } \\
\text { regional integrationstrategies }\end{array}$ & 2011 \\
\hline $\begin{array}{l}\text { Investigaciónbib } \\
\text { liotecológica }\end{array}$ & $\begin{array}{l}\text { Artigo/ } \\
\text { México }\end{array}$ & $\begin{array}{l}\text { Galina Russell, } \\
\text { Isabel. }\end{array}$ & $\begin{array}{l}\text { La visibilidad de los recursos } \\
\text { académicos: Una revisión crítica del } \\
\text { papel de losrepositoriosinstitucionales } \\
\text { y elaccesoabierto }\end{array}$ & 2011 \\
\hline $\begin{array}{l}\text { Revista Médica } \\
\text { Herediana }\end{array}$ & $\begin{array}{l}\text { Artigo/ } \\
\text { Perú }\end{array}$ & Miyahira, Juan. & $\begin{array}{l}\text { ¿Más revistas científicas o } \\
\text { repositoriosinstitucionales de } \\
\text { accesoabierto? }\end{array}$ & 2011 \\
\hline ACIMED & $\begin{array}{l}\text { Artigo/ } \\
\text { Cuba }\end{array}$ & \begin{tabular}{|l|} 
Díaz Rodríguez, \\
Yoselyn; Sánchez \\
Tarragó, Nancy. \\
\end{tabular} & $\begin{array}{l}\text { Propuesta para eldiseño de } \\
\text { unrepositorio de tesisdoctorales para el } \\
\text { sector Saluden Cuba }\end{array}$ & 2010 \\
\hline $\begin{array}{l}\text { Actas } \\
\text { Urológicas } \\
\text { Españolas }\end{array}$ & $\begin{array}{l}\text { Artigo/ } \\
\text { Espanh } \\
\text { a }\end{array}$ & $\begin{array}{l}\text { Sánchez-Martín, } \\
\text { Francisco M.; Millán } \\
\text { Rodríguez, Félix; } \\
\text { VillavicencioMavric } \\
\text { h, Humberto. } \\
\end{array}$ & $\begin{array}{l}\text { La Iniciativa Open Access (OAI) enla } \\
\text { literatura científica }\end{array}$ & 2009 \\
\hline $\begin{array}{l}\text { Información, } \\
\text { cultura y }\end{array}$ & $\begin{array}{l}\text { Artigo/ } \\
\text { Argenti }\end{array}$ & De Volder, Carolina. & $\begin{array}{l}\text { Los repositorios de accesoabiertoen } \\
\text { Argentina: situaciónactual. }\end{array}$ & 2008 \\
\hline
\end{tabular}




\begin{tabular}{|l|l|l|l|l|}
\hline sociedad & na & & & 2007 \\
\hline ACIMED & $\begin{array}{l}\text { Artigo/ } \\
\text { Cuba }\end{array}$ & $\begin{array}{l}\text { Flores Cuesta, Gilda; } \\
\text { Sánchez Tarragó, } \\
\text { Nancy. }\end{array}$ & $\begin{array}{l}\text { Los repositoriosinstitucionales: } \\
\text { análisis de lasituación internacional y } \\
\text { principiosgenerales para Cuba }\end{array}$ & 2007 \\
\hline ACIMED & $\begin{array}{l}\text { Artigo/ } \\
\text { Cuba }\end{array}$ & $\begin{array}{l}\text { Sánchez Tarragó, } \\
\text { Nancy. }\end{array}$ & $\begin{array}{l}\text { El movimiento de accesoabierto a } \\
\text { lainformación y laspolíticas nacionales } \\
\text { e institucionales de autoarchivo }\end{array}$ & 2006 \\
\hline $\begin{array}{l}\text { Perspectivas em } \\
\text { Ciência da } \\
\text { Informação }\end{array}$ & $\begin{array}{l}\text { Artigo/ } \\
\text { Brasil }\end{array}$ & $\begin{array}{l}\text { Moreno, Fernanda } \\
\text { Passini; Leite, } \\
\text { Fernando César } \\
\text { Lima; Arellano, } \\
\text { Miguel } \\
\text { ÁngelMárdero. }\end{array}$ & $\begin{array}{l}\text { Acesso livre a publicações e } \\
\text { repositórios digitais em ciência da } \\
\text { informação no Brasil }\end{array}$ & \\
\hline
\end{tabular}

Fonte: Dados da pesquisa, coletados no SciELO em 25 jul. 2018.

Os periódicos com maior número de publicação foram: ACIMED (3), Revista Cubana de Información em Ciencias de la Salud (3), Revista Interamericana de Bibliotecología (4); os demais periódicos publicaram 1 e 2 artigos. Os anos de maior representatividade em publicações no SciELO foram, 2011 (4), 2013 (5), 2015 (5), os demais com 1 e 2 publicações. Das 25 publicações, 11 são da área da ciência da Informação, outras 10 da saúde, as outras 4 publicações são de áreas correlatas.

Não é demais ressaltar que SciELO é uma rede internacionalmente conhecida por ser mobilizadora da publicação de pesquisas científicas de alto padrão em acesso aberto, principalmente na área da saúde, dando visibilidade e impacto as publicações de acesso aberto, por disponibilizar o acervo também na Web of Science.

Porém, algumas questões de política de arquivamento do SciELO impedem que outras revistas e meios de publicação divulguem suas pesquisas na base. A rede requer "alto padrão" de publicação, isso quer dizer que segue critérios com base nos extratos do Qualis da agência regulamentadora Capes-Coordenação de Aperfeiçoamento de Pessoal de Nível Superior do Brasil (2018). A Capes avalia todos os periódicos e publicações das instituições de pesquisa e emite um extrato, grau de qualidade: A1 e A2 são consideradas as melhores; B1, B2, B3, B4, B5 são consideradas medianas e as publicações com extrato C não são consideradas com critérios suficientes de qualidade. Cabe salientar que esses parâmetros de avaliação estão em processo de modificações. Por esse motivo, muitas revistas e publicações não estão disponíveis no SciELO.

Analisando os dados das duas bases, obteve-se um perfil dos estudos, que em geral, representam três vieses de análise: 
a) Estudos de casos em repositórios de universidades e instituição de pesquisa $($ BDTD $11+5$ SciELO = 16);

b) Estudos de repositório em âmbito internacional e nacional: América latina, Caribe, Argentina, Cuba e Brasil - (BDTD 3 + 8 SciELO = 11);

c) Análise administrativa e técnica com foco em: indexação, descrição temática e física, recuperação, representação, políticas, visibilidade, gestão, estratégias, tendências, preservação, acesso, diretrizes, compartilhamento, organização, disseminação, padrão $($ BDTD $12+8$ SciELO $=20)$.

Os estudos demonstraram que a preocupação maior é com a aplicação técnica e administrativa nos e dos repositórios de acesso aberto, seguidos dos estudos de caso de repositórios de instituições de ensino e pesquisa. E por último, os estudos com foco em repositórios nacionais e internacionais.

Babini (2016) lembra certas fragilidades das estruturas de publicação científica de acesso aberto como a importância das instituições em aprovarem as políticas de informação para o acesso aberto, predominância em publicar no idioma inglês sendo reconhecido como mérito, os indicadores do acesso aberto ainda não são utilizados como indicadores da avaliação de pesquisas, políticas de pesquisa e agências de fomento são influenciadas pelo lobby das publicadoras comerciais internacionais no modelo de Article Processing Charges APC, não existem confederações formais do acesso aberto em âmbito regional. Esses são reflexos apresentados nos estudos analisados.

Outro aspecto que pode se observar é perfil dos pesquisadores; na BDTD são estudos brasileiros, por isso os vieses $a$ e $c$ foram mais representativos que o $b$, do qual os estudos seguem um viés mais amplo e global.

Por mais que se tenha vários aspectos para estudar e melhorar, os repositórios de acesso aberto estão em crescente aplicação, em âmbito nacional, internacional e institucional basta observar como tem crescido o número de estudos com o passar dos anos. Shintaku et al. (2013) enfatizam que, entre as inúmeras iniciativas para compartilhar conteúdos digitais, os repositórios têm sido um ambiente apreciado por diversas instituições, principalmente as de ensino e pesquisa.

Há vários casos de sucesso de uso de repositórios como profícuo ambiente de disseminação de conteúdos em ambiente digital, por exemplo, a Nasa, PubMed, Arxiv.org, 
CERN entre muitos outros órgãos que são mundialmente conhecidos. ${ }^{23}$ Os softwares livres que são empregados para o uso de repositórios podem ser customizados e adaptados para as necessidades de cada instituição; assim, viabilizam o atendimento das necessidades de gerenciamento e organização da informação em meio eletrônico, além de promover a preservação digital e o amplo acesso desses acervos aos usuários.

\section{CONCLUSÕES}

O estudo mostrou que o Brasil tem desenvolvido pesquisas, ainda que tímidas, com foco na aplicação de repositórios, sejam eles de cunho internacional, nacional ou institucional. Em geral os dados demostraram que os repositórios de acesso aberto são recursos estruturados benéficos para organização, gestão e preservação da informação em diversos suportes informacionais. Assim como o emprego de softwares livres em repositórios, a aplicação de canais de comunicação e acesso de conteúdo em diretórios, bases de dados e sistemas de editoração são movimentos que têm desenvolvido na cultura da ciência aberta - as várias iniciativas deste segmento assim o atestam.

Pode-se dizer que os repositórios de acesso aberto têm ganhado espaço exponencial, pois se no princípio eram alguns poucos cientistas que postavam seus textos em servidores da web, hoje são milhares de instituições renomadas, envolvidas no compromisso de socializar as práticas e teorias resguardadas em arquivos digitais, nos mais diversos tipos e formatos de documentos. De fato, ao acompanhar a evolução no ROAR, nota-se 133 países com repositórios cadastrados no sistema.

A inclusão social e digital revela a importância da informação na vida das pessoas, com poder de transformar a sociedade, no desenvolver de ações, opiniões, e ampliar conhecimentos sendo elementos vitais para a sobrevivência da humanidade.

Cabe salientar que os profissionais da informação precisam conhecer mais a fundo sobre o desenvolvimento tecnológico e científico que enreda o mundo do acesso aberto, a fim de inferir o conhecimento da área nestas estruturas informacionais de acesso e organização de informação em ambientes como os repositórios.

\footnotetext{
23 Ver mais em: https://repositories.webometrics.info/en/transparent.
} 
Lembra-se que esse é um estudo preliminar e são necessários mais estudos a respeito de aplicação, perfil da comunidade, representação do conteúdo e relevância de recuperação para que se tenha sucesso na sua aplicação, assim como o desenvolvimento de políticas de organização, políticas de gestão e políticas de acesso, acessibilidade, ações de inclusão digital para pessoas com diferente deficiências, interoperabilidade, linguagem de acesso e as métricas de uso e de acesso - todos esses elementos podem ser objetos de estudo, principalmente na área da Ciência da Informação.

Dessa forma, enfatiza-se a necessidade de continuar com estudos direcionados aos repositórios e softwares livres em sistemas que possibilitem eficiente representação do conhecimento humano de interesse social.

Conclui-se que o cenário do acesso aberto tem mudado o fazer-pensar/sabercientífico e tecnológico de diversos segmentos. O movimento propiciou o acesso à informação científica em escala global e muitos se beneficiam da informação disponível na web. 


\section{REFERÊNCIAS}

ALVARENGA, Lídia. Modelagem conceitual e sistemas de organização de conhecimento; uma reflexão baseada em experiências acadêmicas e profissionais no Brasil no domínio da Biblioteconomia e Ciência da Informação. In: ISKO BRASIL, 2013, Rio de Janeiro, RJ. Anais [...]. Rio de Janeiro: FUNDEPE, 2013.

ALPERIN, Juan Pablo; BABINI; Dominique, FISCHMAN; Gustavo (ed.). Open Access Indicators and Scholarly Communications in Latin America. Buenos Aires: UNESCO, 2014.

ATKINS, Daniel et al. RCUK Review of e-Science 2009 building a UK foundation for the transformative enhancement of research and innovation. Reino Unido- Polaris House: Research Councils UK: The Royal Society, 2009.

ARXIV.ORG. About. 2019. Disponível em: https://arxiv.org/about. Acesso em: 6 nov. 2019.

BABINI; Dominique. Scholarly Community led open access in Latin America looking for a shared vision with other developing regions. In: CONFERENCE ON ELECTRONIC PUBLISHING (Council for the Development of Social Science Research in Africa CODESRIA), 4., 2016, Senegal. Anais[...]. Dakar: CODERSIA, Apr. 2016.

BDTD-Biblioteca Digital Brasileira de Teses e Dissertações. Pesquisa: "acesso aberto" + repositório. 2018a. Disponível em: http://bdtd.ibict.br/vufind/Search/Results?lookfor=\% 22acesso+aberto\%22+\%2B +reposit \% C3\% B3rio\&type=AllFields\&limit=20\&sort=year.

Acesso em: 25 jul. 2018.

BDTD-Biblioteca Digital Brasileira de Teses e Dissertações. Pesquisa: Repositório + acesso aberto. 2018b. Disponível em: http://bdtd.ibict.br/vufind/Search/Results?lookfor=Reposit\%C3 $\%$ B3rio $+\% 2 \mathrm{~B}+$ acesso+aberto\&type=Subject\&limit=20\&sort=year. Acesso em: 25 jul. 2018.

COORDENAÇÃO DE APERFEIÇOAMENTO DE PESSOAL DE NÍVEL SUPERIOR CAPES. Qualis. 2018. Disponível em: https://sucupira.capes.gov.br/sucupira/public/consultas /coleta/veiculoPublicacaoQualis/listaConsultaGeralPeriodicos.jsf. Acesso em: 11 ago. 2018.

CASTELLS, Manuel. Aula Magna: Os efeitos da informação em rede. Florianópolis: UDESC, 14 maio, 2015. Disponível em: http://www.udesc.br/?idNoticia=12925. Acesso em: 02 abr. 2019.

CHAUÍ, Marilena. Convite à filosofia. 13. ed. São Paulo: Ática, 2003.

CUNHA; Murilo Bastos da. Para saber mais: fontes de informação em ciência e tecnologia. 2. ed. Brasilia: Briquet de Lemos, 2016.

COUNCIL OF THE EUROPEAN UNION. The transition towards an Open Science system, Council conclusions (adopted on 27 May 2016). Brussels, 2016. Disponível em: http://data.consilium.europa.eu/doc/document/ST-9526-2016-INIT/en/pdf. Acesso em: 16 maio 2019. 
CRESWELL, J. W. Projeto de pesquisa: métodos qualitativo, quantitativo e misto. 3. ed. Porto Alegre: Artmed, 2010.

DATAVERSE. About. 2018. Disponível em: http://dataverse.org/about/. Acesso em: 08 jun. 2019.

DATA CITATION SYNTHESIS GROUP. Joint Declaration of Data Citation Principles. Martone M. (ed.) San Diego, CA: FORCE11, 2014. Disponível em: https://www.force11.org/ group/joint-declaration-data-citation-principles-final. Acesso em: 23 abr. 2019.

DIRECTORYOF OPEN ACCESS BOOKS - DOABOOKS. Sobre. 2018. Disponível em: https://www.doabooks.org/. Acesso em: 16 maio 2019.

DIRECTORY OF OPEN ACCESS JOURNAL - DOAJ. About. 2019. Disponível em: https://doaj.org/about. Acesso em: 16 maio 2019.

DIRECTORY OF OPEN ACCESS SCHOLARLY RESOURCES - ROAD. About. 2018. Disponível em: http://road.issn.org/en. Acesso em: 08 maio 2019.

DIRECTORY OF OPEN ACCESS REPOSITORIES - OPENDOAR. FAQ. University of Nottingham, UK. 2006-2017. Disponível em: http://www.opendoar.org/faq.html. Acesso em: 07 jul. 2019.

DIRECTORY OF OPEN ACCESS REPOSITORIES - OPENDOAR. About. 2018. Disponível em: http://www.opendoar.org. Acesso em: 16 abr. 2019.

DIAS, Guilherme Ataíde; DELFINO JUNIOR, João Bosco; SILVA, José Wendell Morais. Open journal systems - OJS: migrando um periódico científico eletrônico para um sistema automatizado de gerência e publicação de periódicos científicos eletrônicos. Informacao \& Sociedade: Estudos, João Pessoa, v. 17, n. 2, p. 75-82, 2007.

EUROPEAN UNIVERSITY ASSOCIATION. EUA's open access checklist for universities: a practical guide on implementation. 2015. 24 p. Disponível em: https://eua.eu/ downloads/publications/euas \%20open $\% 20$ access $\% 20$ checklist $\% 20$ for $\% 20$ universities $\% 20 \mathrm{a} \%$ 20practical\%20guide\%20on\%20implementation.pdf. Acesso em:13 maio 2018.

FOSTER. About. 2018. Disponível em: https://www.fosteropenscience.eu/about\#theportal. Acesso em: 16 maio 2019.

FLICK, Uwe. Introdução à pesquisa qualitativa. Trad. Joice Elias $\quad$ Costa. $3 . \quad$ ed. São Paulo: Artmed. 2009.

GLEICK, James. A informação: uma história, uma teoria, uma enxurrada. São Paulo: Companhia das Letras, 2013.

HARVARD. Repositório central de Harvard: About. 2018. Disponível em: https://dash.harvard.edu/. Acesso em: 24 maio 2019. 
IBICT. Repositórios Digitais. 2018. Disponível em: http://www.ibict.br/informacao-paraciencia-tecnologia-e-inovacao\%20/repositorios-digitais/historico. Acesso em: 20 jan. 2019.

LIBRARY PUBLISHING COALITION. Library Publishing Directory. Atlanta: Library Publishing Coalition, 2015. Disponível em: http://www.librarypublishing.org/sites/library publishing.org/files/documents/lpc_dir_2015lpd.pdf. Acesso em: 26 abr. 2019.

MORALES MORANTE; Luís Fernando. Visibilid e impacto de las revistas peruanas de Ciencias Sociais en acesso abierto. Biblios: Journal of Librarianship and Information Science, Lima, n. 65, p. 29-51, dez. 2016. DOI: http://dx.doi.org/10.5195/biblios.2016.320.

OPEN ACCESS SCHOLARLY PUBLISHERS ASSOCIATION- OASP. Conference. 2018. Disponível em: https://oaspa.org/events/. Acesso em: 09 abr. 2019.

PACKER, A. L.; SALES, D.; RODRIGUES, H. Periódicos das Ciências Humanas e Sociais Aplicadas fazem uso crescente das redes sociais. SciELO em Perspectiva: Humanas, [online], 04 fev. 2016.

PADRÃO DE METADADOS DE OBJETOS DE APRENDIZAGEM - OBAA. Sobre. 2018. Disponível em: http://www.portalobaa.org/padrao-obaa. Acesso em: 16 abr. 2019.

PUBLIC KNOWLEDGE PROJECT - PKP. Open Journal System. 2018a. Disponível em: https://pkp.sfu.ca/ojs/. Acesso em: 07 maio 2019.

PUBLIC KNOWLEDGE PROJECT - PKP. OJS Stats. 2018b. Disponível em: https://pkp.sfu.ca/ojs/ojs-usage/ojs-stats/. Acesso em: 01 maio 2019.

RANKING WEB OF REPOSITORIES. Consejo Superior de Investigaciones Científicas (CSIC). 2018. Disponível em: https://repositories.webometrics.info/en/About_Us. Acesso em: 02 jul. 2018.

RANKING WEB OF REPOSITORIES. Transparent Rankings: All repositories. 2019. Disponível em: https://repositories.webometrics.info/en/transparent. Acesso em: 12 nov. 2019.

RAMPAZZO, Lino. Metodologia científica: para alunos dos cursos de graduação e pósgraduação. 7. ed. São Paulo: Loyola, 2013.

REGISTRY OF OPEN ACCESS REPOSITORIES - ROAR. Brazil DSpace. 2016. Disponível em: http://roar.eprints.org/cgi/roar_search/advanced?location_country=br\&soft ware=dspace \& type=institutional\&order=-activity_low\%2F-date. Acesso em: 02 fev. 2019.

REGISTRY OF OPEN ACCESS REPOSITORY MANDATES AND POLICIES ROARMAP. Registro de políticas e mandatos de repositórios de acesso aberto. Brazil. 2018a. Disponível em: http://roarmap.eprints.org/view/country/076.html. Acesso em: 01 fev. 2019. 
REGISTRY OF OPEN ACCESS REPOSITORY MANDATES AND POLICIES ROARMAP. Dados da pesquisa. 2018b. Disponível em: http://roarmap.eprints.org/view/ country/076.html. Acesso em: 17 abr. 2019.

SciELO LIVROS. O que é e como participar? São Paulo: ABEU SciELO, setembro 2018. Disponível em: http://books.scielo.org/wp-content/uploads/2016/09/Guia_SciELO_Livros 20160923 PT.pdf. Acesso em: 11 jan. 2019.

SciELO. Busca: open access + repositories. 2018. Disponível em: https://search.scielo.org/ $? \mathrm{q}=+$ open + access +++ repositories\&lang $=\mathrm{pt} \&$ count $=50 \&$ from $=0 \&$ output $=$ site \&sort $=\&$ format $=$ summary $\& \mathrm{fb}=\&$ page $=1$. Acesso em: 11 jul. 2018.

SIMMONS College. Open Access Directory. Boston, 2018. Disponível em: http://oad.simmons.edu/oadwiki/Main_Page. Acesso em: 17 jan. 2019.

SHINTAKU, Milton; BRITO; Ronnie Fagundes de; CARVALHO NETO, Sílvio. A avaliação dos portais de revistas brasileiros implementados com o SEER/OJS. Informação \& Sociedade: Estudos, João Pessoa, v.24, n. 2, p. 139-148, maio/ago. 2014.

SHINTAKU, Milton et al. Banco Internacional de Objetos Educacionais - BIOE. In: Congresso internacional de Humanidades, 16., 2013, Brasília. Anais[...]. Brasília: UnB, 2013. Disponível em: http://2014.revistaintercambio.net.br/24h/pessoa/temp/anexo/1/421/749.pdf. Acesso em: 14 nov. 2019.

SNIJDER, Ronald. Evaluating the Impact of the FWF-E-Book-Library Collection in the OAPEN Library: An Analysis of the 2014 Download Data. D-Lib Magazine, [S.l.], v. 21, n. $7 / 8,2015$.

UNESCO: COAR- Statement on Open Access. UNESCO, 9 set. 2016. Disponível em: http://www.unesco.org/new/fileadmin/MULTIMEDIA/HQ/CI/CI/pdf/news/coar_unesco_oa_s tatement.pdf. Acesso em: 12 fev. 2019.

UNESCO: Global Open Access Portal (GOAP). UNESCO, 9 set. 2016. Disponível em: http://www.unesco.org/new/en/communication-and-information/portals-and-platforms/goap/. Acesso em: 28 mar. 2019.

UNION OF INTERNATIONAL ASSOCIATIONS (UAI). UIA's History 1907 - 2015 Union of International Associations. 2018. Disponível em: https://uia.org/history. Acesso em: 28 mar. 2019.

UNIVERSIDADE FEDERAL DA BAHIA. Repositório Institucional. Salvador: UFBA, 2018. Disponível em: https://repositorio.ufba.br/ri/. Acesso em: 28 mar. 2018.

UNIVERSIDADE FUMEC. Faculdade de Ciências Empresariais - FACE. Projetos, Dissertações e Teses em Sistemas de Informação e Gestão do Conhecimento. Belo Horizonte: FUMEC, 2012-2016. Disponível em: http://www.fumec.br/revistas/sigc/about/ editorialPolicies\#focusAndScope. Acesso em: 02 jul. 2018. 
WORLD BANK. OPEN GOVERNMENT DATA TOOLKIT. Starting an Open Data Initiative. 2018. Disponível em: http://opendatatoolkit.worldbank.org/en/starting.html. Acesso em: 21 fev. 2019. 